\title{
Comparing marginal bone height changes around immediately and delayed implant- retained mandibular overdentures in controlled diabetic patients: a randomized clinical study
}

Eman Mostafa Ahmed Ibraheem ${ }^{1 *}$, Hoda Gaafar Hassan Hammad² and Ahmed Mostafa Esmat El-Sisy ${ }^{1}$

\begin{abstract}
Purpose: This study was conducted to evaluate the marginal bone height changes around dental implants in mandibular implant-retained complete acrylic overdentures using cone beam computed tomography (CBCT) with implementation of both immediate and delayed loading protocols in controlled type II diabetes mellitus (DM) patients.

Patients and methods: Twenty completely edentulous controlled diabetic patients were selected to participate in this study to receive mandibular implant-retained overdentures. Then, the study patients were randomly divided into two equal groups according to the loading protocol: group I, ten patients had received complete overdentures retained with two implants and two ball attachments while applying the immediate implant loading protocol and group II, ten patients had received complete overdentures retained with two implants and two ball attachments while applying the delayed implant loading protocol. For each patient, a computer-guided surgical stent was prepared for CBCT assessment to properly determine the dimensions and angulations of the two implants that were inserted in the inter-foraminal region. Afterward, the dental prosthetic was loaded, and a second $C B C T$ was done for each patient to measure the marginal alveolar bone height. Then CBCTs were periodically performed after a period of 6 and 12 months after prosthetic loading in order to monitor the changes in marginal bone height surrounding the inserted dental implants.

Results: Statistical analysis of obtained records revealed no significant difference between the two loading protocols in the studied groups.

Conclusion: Marginal bone height changes around immediately and delayed implant-retained mandibular over dentures seem comparable in controlled type II diabetic patients.

Trial registration: Trial registration number: 16086; date of registry, November 2016; date of the research, June 2017

Keywords: Implant overdentures, Flapless dental implant, Immediate dental implant loading, Controlled diabetes mellitus, Delayed dental implant loading, Marginal bone height loss, CBCT, Osseointegration
\end{abstract}

\footnotetext{
* Correspondence: eman1mostafa@yahoo.com

${ }^{1}$ National Research Centre, Cairo, Egypt

Full list of author information is available at the end of the article
} 


\section{Introduction}

Actually, teeth loss is followed by human alveolar bone resorption; this physiologic phenomenon decreases retention and stability of complete dentures. Moreover, this problem is more prominent in mandibular complete dentures than the maxillary ones. Consequently, patient experiences reduced chewing efficiency and loss of self-confidence (Doundoulakis et al. 2003; Misch 2008; Albaker 2012). Rehabilitation of completely edentulous mandible using dental implant retained (by two dental implants) overdenture was found a predictable successful long-term treatment modality (Chiapasco et al. 2001). Moreover, implant-retained overdentures using two separate titanium implants had been reported to improve the function and had realized a success rate of about $97 \%$ to $100 \%$ (Liddelow and Henry 2007). Subsequently, as a dental implant was inserted into bone and subjected into function, supporting alveolar bone remodeling became a critical aspect for implant survival. Systemic disorders and metabolic diseases might influence osseointegration of dental implants that retain complete overdentures (Oates et al. 2013).

Delayed loading of mandibular implant-retained overdentures had been an established treatment protocol that was supported by sound evidence of the long-term monitored changes in marginal bone levels (Meijer et al. 2004; Naert et al. 2004; Meijer et al. 2009) and it was called "Model for Implant Success" (Schwartz-Arad et al. 2005). In last decade, both immediate and early dental implant loading protocols were strongly promoted commercially to take advantage of short healing periods and improved patient outcomes. However, without evident long-term data supporting those implant loading protocols, it was still premature to consider them clinically acceptable (Zarb and Albrektsson 1998). Marginal bone height stability had been considered as one of the parameters of successful osseointegration (Wennström and Palmer 1999; Albrektsson and Zarb 1993). In addition, various factors were affecting success rate of dental implants including the biomechanics. Accordingly, occlusal overload was a primary aspect of such key biomechanical factors, which jeopardize dental implant osseointegration because it was generating peri-implant strain and it was producing peri-implant marginal bone loss (Kushaldeep et al. 2018; Rani et al. 2017)

Diabetes mellitus represents a chronic metabolic endocrinal disorder that occurs when the pancreatic beta cells are not producing sufficient insulin in the blood circulation or when human body is unable to effectively utilize the secreted insulin. In addition, diabetes especially if uncontrolled is associated with high prevalence of microvascular diseases, delayed complicated wound healing, and impaired immune response to infection (Ma et al. 2010; Albrektsson et al. 2009). However, diabetes mellitus was remaining a relative contraindication for titanium dental implant therapy; well-controlled diabetic patients were indicated for implantology, and diabetic patients who are lacking proper glycemic control were denied from dental implant treatment (Khader et al. 2006).

However, clinical trials had reported comparable peri-implant marginal bone level changes in conventionally and immediately loaded implants, and their statistical results were contradictory (Engelhardt et al. 2015). Studies were suggesting that immediate loading of dental implant might induce micromotions, which might interfere with primary stability of the placed implant, stimulate fibrous tissue formation around it, and subsequently lead to implant loss. Although there was no definitive clinical documentation, which related immediate loading to implant failure, low frequency micromotion was reported that to enhance osseogenesis (Goodman et al. 1993; Goodman 1994; Vidyasagar and Aspe 2003). Therefore, the initial primary stability (micromotion) of dental implant was considered the common factor between delayed loading and immediate loading of inserted implants. Also, close approximation of dental implant to alveolar bone at time of implant placement might be another fundamental criterion in achieving successful osseointegration (Szmukler-Moncler et al. 1998).

Currently, the most reliable method for discriminating success of osseointegrated implants and evaluation of marginal bone level changes around dental implants is CBCT (Albrektsson et al. 2009). Therefore, a standardized radiographic technique (CBCT) played a crucial role for sequential reliable monitoring of marginal bone level changes in mandibular implant-retained overdentures with two different loading protocols.

\section{Aim}

This study was conducted to evaluate marginal bone height changes bone in immediately and delayed loaded mandibular implant-retained overdentures in controlled type II diabetic patients.

\section{Patients and methods}

Ethical approval

The study had been approved by the Ethical Committee of the National Research Centre (NRC), Egypt.

\section{Materials}

Materials Dental implants (Nobel-Guide, Nobel Biocare, Gothenburg, Sweden), software (Nobel Clinician, Nobel Biocare), dental implants (Nobel Speedy Groovy RP, Nobel Biocare), anchor pins (Guided Anchor Pin w1.5 mm, 
Nobel Biocare), pressure-indicating silicone (Fit Checker, GC, Tokyo, Japan), local anesthesia (Lidocaine hydrochloride $2 \%$ ) were included.

The instruments used were a drill (Guided Start Drill, Nobel Biocare), twist drills with diameters of 2.0, 2.8, 3.2, and $3.4 \mathrm{~mm}$ (Guided Twist Drill, Nobel Biocare), and a removable sleeve (Guided Drill Guide, Nobel Biocare).

\section{Patient selection criteria}

- Twenty male completely edentulous patients were selected from the Medical Excellence Centre, National Research Centre, Cairo, Egypt.

- Patient age ranged from 55 to 70 years old.

- Patients were controlled diabetes mellitus; type II (glycosylated hemoglobin level was not exceeding $7.5 \%$ through all the study period).

- All selected patients were completely edentulous at least 6 months at the beginning of the study.

- Thorough intra-oral and extra-oral examinations were done for all study patients.

\section{Patients grouping}

A total of 20 patients were randomly divided into two equal groups (group I and group II) according to the implant loading protocol.

Group I: ten patients received 20 implants that were immediately loaded with ball attachment retained overdentures.

Group II: ten patients received 20 implants that were delayed loaded with ball attachment retained overdentures.

\section{Pre-surgical prosthodontic management}

- Maxillary and mandibular complete dentures were constructed for each patient.

- Patients had received their dentures after making the necessary adjustments.

- Patients were recalled 3 days, 1 week, and 2 weeks after denture insertion to overcome any arising problem regarding the mandibular denture.

- Patients were instructed to wear their mandibular complete dentures for 1 week before CBCT scan.

\section{Preoperative radiographs}

- Radiographic template: for all patients, the constructed mandibular complete denture was used as a radiographic template after making certain modifications.

- Gutta-percha markers were inserted into the fitting surface of the mandibular denture at different axial planes to act as radio-opaque markers.
- Pre-operative cone beam computed tomography (CBCT) scan was made for each patient while wearing his radiographic template.

\section{Construction of surgical stents (Lambade et al. 2014)}

- A pre-operative CBCT scan was performed for each patient using the radiographic template by double scanning technique.

- The patient was instructed for clenching on the radiographic template.

- By coinciding the radio-opaque markers, two sets of "Digital Imaging and Communication in Medicine" (DICOM) files were superimposed.

- A virtual three-dimensional image of mandibular radiographic template was created by the software planning of the machine.

- Relying on the commercially available planning software, optimal position of two threedimensionally parallel dental implants was virtually simulated in inter-foraminal mandibular region.

\section{Implants insertion}

- Two dental implants were inserted in mandibular canine areas bilaterally using flapless technique and with the aid of the CAD/CAM surgical guide.

- Furthermore, whole components of the ball and socket attachment that were included in denture space were confirmed.

- Three anchor pins were inserted in the virtually decided places for surgical guide fixation (Fig. 1).

- Sufficient local anesthesia was given.

- The surgical guide was fixed in place by firm finger compression till being stabilized with the anchor pins.

- After fixation, sufficient local anesthesia was given through sleeves of the surgical guide.

- Mucosa covering the ridge in the areas of interest was removed with the tissue punch.

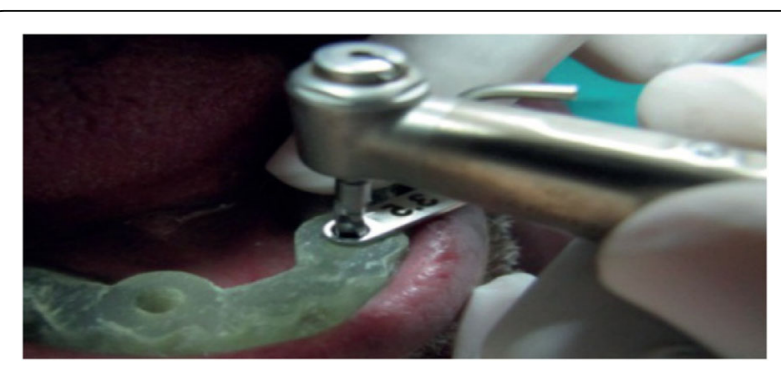

Fig. 1 A photograph showing drilling with the aid of computer guided surgical stent 
- The pilot drill was utilized to create the initial implant bed followed by subsequent drills. Drilling was made through removable sleeves inserted into the surgical guide with diameters coinciding with each drill.

- Implants were completely seated into their corresponding sites via the surgical guide and sleeves. Then, the surgical guide was removed and the covering screw of the implant was placed.

- Immediately after surgery and for 1 week, all patients were instructed to keep wearing their dentures $24 \mathrm{~h} /$ day except at bed time and time of denture cleaning.

- Postoperatively, the constant wearing of dentures was minimizing the associated oral swelling that might physically hinder denture reinsertion by the patient.

- Furthermore, prescription of postoperative medications including antibiotics, amoxicilin 875 $\mathrm{mg}$ and clavulante potassium $125 \mathrm{mg}$ (Glaxo Smithkline, UK); and analgesics/anti-inflammatory, diclolfenac sodium $50 \mathrm{mg}$ (Novartis pharmaceuticals, Egypt). Both were prescribed twice a day for 7 days.

- For the first 2 weeks, patients were instructed to rinse their mouths with chlorhexidine (chlorhexidine gluconate $0.1 \%$, thymol $0.06 \%$, menthol $0.042 \%$, and clove oil $0.06 \%$ ) mouth wash three times per day.

- Moreover, patients were informed to start gentle tooth brushing around the individual implant attachments only 1 week after implant surgery.

\section{Loading protocol}

Concerning group I patients, within $48 \mathrm{~h}$ after surgery, the dental implants were immediately loaded using ball and socket attachments. Moreover, the denture occlusion was perfectly adjusted in order to avoid any premature contact in centric as well as eccentric jaw relation. Regarding group II patients, implant fixtures were buried 3 to 4 months after surgery. Afterward, successful bone osseointegration was verified clinically and radiographically and after that dental implants were loaded using ball and socket attachments.

\section{Post-surgical prosthodontic management (ball abutment pick up)}

The ball abutment pick up procedure was performed as the following successive steps (Shor et al. 2007):

- The covering screws were removed and the ball attachments were screwed directly into dental implants.
- Pick-up procedure was started by slipping of orthodontic separators around ball abutments to obliterate the space beneath the metal housing in order to avoid trap of lower denture acrylic resin lock into those undercuts. Then, the ball metallic housings were applied on the ball abutments.

- Furthermore, patients' constructed mandibular dentures were completely relieved opposite to ball attachments' sites and a prepared mix of self-cured acrylic resin (dough stage) was placed in the two relieved areas of the denture. Then, denture was inserted in the patient's mouth.

- The auto-cured acrylic resin was allowed to set while the patients were occluding in centric relation with minimum pressure, because excessive biting might force the denture toward the soft tissues and therefore, accurate seating of denture would be jeopardized.

- Lastly, after complete setting of the cold-cured resin, lower dentures with the ball housings already picked up into its fitting surface were removed from patient mouth, trimmed, finished and polished (Figs. 2 and 3).

\section{Postoperative radiographic evaluation of marginal bone height (Sato et al. 2016)}

- Postoperatively, CBCTs were performed immediately after denture prosthetic loading, after 6 and 12 months after implant loading in order to assess any marginal alveolar bone height changes. Also, the distances between the observed crestal bone level and dental implant shoulder were accurately determined.

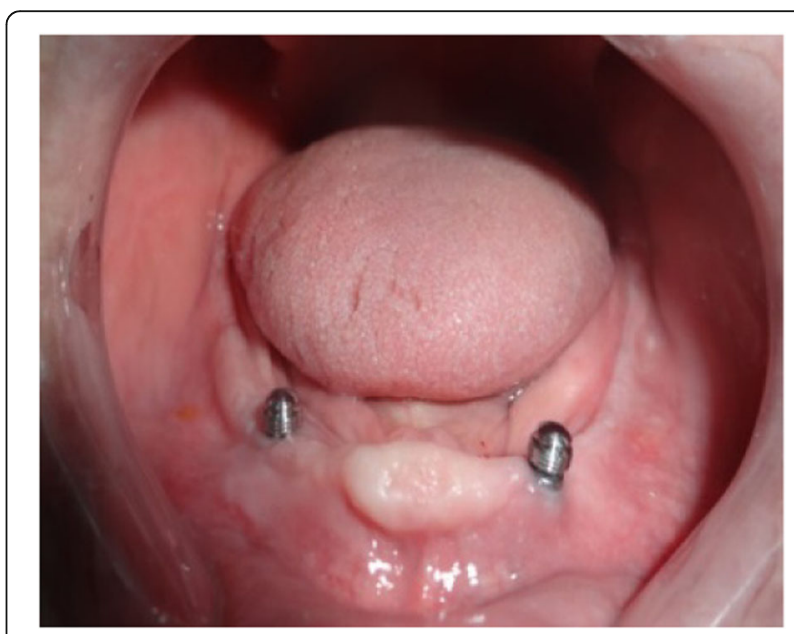

Fig. 2 A photograph showing the ball attachments applied upon mandibular dental implants 


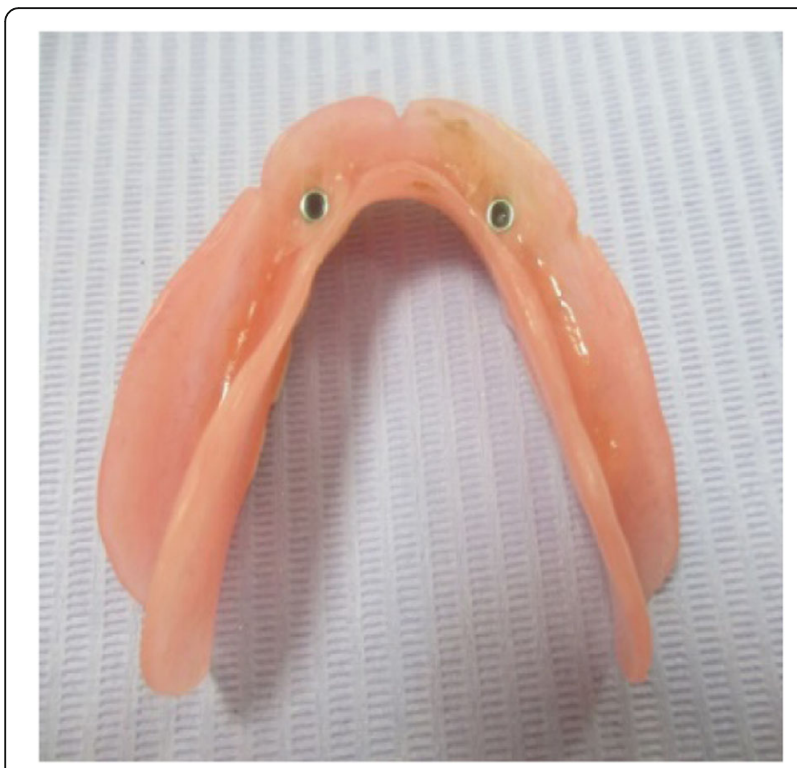

Fig. 3 A photograph showing the ball housings picked up into fitting surface of lower denture

- Those distances were measured as follow: one image representing $1 \mathrm{~mm}$ buccolingual slice; immediately mesial to mandibular implants and another image for $1 \mathrm{~mm}$ buccolingual slice; immediately distal to lower implants.

\section{Results}

At 12 month, all study patients were classified as surviving participants and they had reported implant 100\% success rate. Statistical analysis was performed with SPSS $20^{\circ 1}$, Graph Pad Prism ${ }^{\circ 2}$ and Microsoft Excel $2016^{3}$ with significant level set at $P \leq 0.05$. Data were presented as means $(M)$ and standard deviation (SD).

Concerning group I (the inserted dental implants were immediately loaded), the $M \pm \mathrm{SD}$ of marginal bone loss from mesial surface of dental implants were $0.82 \pm 0.11$ $\mathrm{mm}$ and $1.01 \pm 0.11 \mathrm{~mm}$ after 6 months and after 12 months, respectively, while the $M \pm \mathrm{SD}$ of marginal bone loss from distal implant surfaces were $0.75 \pm 0.09 \mathrm{~mm}$ and $1.04 \pm 0.04 \mathrm{~mm}$ after 6 months and after 12 months, respectively (as shown in Table 1 ).

Regarding group II (delayed loading of inserted dental implants), the $M \pm \mathrm{SD}$ of marginal bone loss from mesial surface of dental implants were $0.79 \pm 0.11 \mathrm{~mm}$ and 1.03 $\pm 0.12 \mathrm{~mm}$ after 6 months and after 12 months, respectively, while the $M \pm \mathrm{SD}$ of marginal bone loss from distal implant surfaces were $0.74 \pm 0.08 \mathrm{~mm}$ and $1.38 \pm$

\footnotetext{
${ }^{1}$ Statistical Package for Social Science, IBM, USA

${ }^{2}$ Graph Pad Technologies, USA

${ }^{3}$ Microsoft Co-operation, USA
}

Table 1 Group I (immediate loading) mesial and distal $(M \pm S D$ in millimeter) implant marginal bone loss after 6 and 12 months

\begin{tabular}{llll}
\hline Group I & $\begin{array}{l}\text { After } 6 \text { months, } \\
M \pm S D(m m)\end{array}$ & $\begin{array}{l}\text { After } 12 \text { months, } \\
M \pm S D(m m)\end{array}$ & $P$ value \\
\hline Mesial & $0.82 \pm 0.11$ & $1.01 \pm 0.11$ & $0.16^{*}$ \\
Distal & $0.75 \pm 0.09$ & $1.04 \pm 0.04$ & $0.007^{* *}$
\end{tabular}

$M$ mean, $S D$ standard deviation, $P$ probability level

*Insignificantly difference

**Significantly difference

$0.23 \mathrm{~mm}$ after 6 months and after 12 months, respectively (as observed in Table 2).

Accordingly, paired $T$ test was performed to compare between $M \pm \mathrm{SD}$ of implant marginal bone loss after 6 and 12 months. However, the implemented test revealed insignificant difference $(P>0.05)$ among mesial surfaces of group I, as well as mesial and distal surfaces of group II, it showed significant difference regarding distal surfaces of group I (as presents in Table 3 and Fig. 4).

Consequently, comparison between the two study groups was performed using the independent $T$ test. The applied test revealed insignificant difference between group I and group II $(P$ value $>0.05)$ regarding mesial implant surfaces (after 6 and after 12 months) and distal implant surfaces (after 6 months), while it showed significant difference $(P<0.05)$ concerning distal surfaces (after 12 months) (as presented in Table 3 and Fig. 4).

\section{Discussion}

DM is characterized by alteration of glucose homeostasis, impaired bone metabolism, and delayed wound healing that increases the risk of oral tissue necrosis and associate infections (Swali 2013). Accordingly, in this study, the significant decrease $(P<0.05)$ in mean distal marginal bone height values of dental implants than the mesial one after 12 months in controlled type II DM might be attributed to altered microvascularity and decreased immune response with presence of oral biofilm. Findings of this study were in agreement with the pathophysiological correlation between DM and impaired wound healing as it seemed complex neuropathic, vascular, biochemical, and immune function abnormalities, where each one is contributing to the impaired tissue repair (Calvet and Yoshikawa 2001; Olson et al. 2000; Beikler and Flemmig 2003).

Marked resorption of crestal alveolar bone was obvious after dental implant surgery involved with incision and mucoperiosteal flap elevation. The marginal bone loss was due to alteration in the microvasculature of the bone periosteum following flap reflection (Romero-Ruiz et al. 2015). Throughout last years, the concept of flapless implantology technique was 
Table 2 Group II (delayed loading) mesial and distal ( $M \pm$ SD in $\mathrm{mm}$ ) implant marginal bone loss after 6 and 12 months

\begin{tabular}{llll}
\hline Group II & After 6 months, $M \pm$ SD $(\mathrm{mm})$ & After 12 months, $M \pm$ SD $(\mathrm{mm})$ & $P$ value \\
\hline Mesial & $0.79 \pm 0.11$ & $1.03 \pm 0.12$ & $0.16^{*}$ \\
Distal & $0.74 \pm 0.08$ & $1.38 \pm 0.23$ & $0.04^{*}$
\end{tabular}

$M$ mean, $S D$ standard deviation, $P$ probability level

*Insignificantly difference

prominent as minimally invasive oral surgical procedures due to many advantages. Those flapless method benefits were intervention with minimum injury to both alveolar bone and oral soft tissues, shortening the time of implant surgery, achieving high level of patient satisfaction, and improving the behavior of healing of peri-implant bone, periosteum, and keratinized mucosa (Romero-Ruiz et al. 2015; Di Giacomo et al. 2012). Those evidences were in coincidence with the insignificant differences $(P>0.05)$ in mean mesial and distal marginal bone loss values in the statistical findings of this study after 6 months.

Postsurgical swelling following implant placement was critical especially for patient wearing implant-retained overdentures because that severe swelling might interfere with placement of the overdenture immediately after surgery. This information was followed and implemented in the study with diabetic patient and good results were achieved (Stricker et al. 2004; Liddelow and Henry 2007).

Indeed, the CBCT was essential for implication of the flapless implant protocol and that association was probably the key of the obtained implant success in controlled type II diabetic patient in the study. The computer-guided implant surgery based on surgical treatment planning with software usage enhanced the clinical outcomes as the dental implants were optimally positioned and accurately angled respecting the various anatomical needs and prosthodontic demands and minimizing risk of bone perforation with flapless implant surgeries (Gastaldi et al. 2017; Thu et al. 2014; Balshi et al. 2006; Sanna et al. 2007).

Stiffness of commercially pure titanium (Ti) or titanium alloy implants is actually several times higher than that of human cortical bone as the modulus of elasticity of the titanium is much greater than that of the bone. Therefore, when the titanium implant is occasionally loaded, stresses will be transferred into the bone, where the highest stress is present in the coronal portion of implant supporting bone. Afterward, strains are increased in the peri-implant bone resulting in micro-cracks; this phenomena is called "Stress Shielding" (Craig and Powers 2012; Bornstein et al. 2014). Following insertion of dental implant, adequate stability in surrounding alveolar bone was essential to enable undisturbed tissue healing and bone osseointegration to develop and also to allow optimum stress distribution from occlusal and masticatory functional loads through dental implant-bone interface.

Dental implant stability requirements for both loading protocols were required. The primary stability was necessary at the time of surgical implant placement, while secondary stability that was achieved in function was essential following osseointegration. Consequently, the stresses upon the immediately loaded $\mathrm{Ti}$ implants did not hinder the osseointegration and it preserved the marginal bone (Bornstein et al. 2014; Alqutaibi and Kaddah 2016).

Prospective clinical studies conducted by Esoposito et al. 2013 (Esposito et al. 2013), Attard and Zarb 2004 (Attard and Zarb 2004) had shown that immediately loaded $\mathrm{Ti}$ implants were acting as support for dental prostheses, and they could osseointegrate providing that both the stresses and implant micro-motions were controlled (Esposito et al. 2013; Attard and Zarb 2004; Ochi et al. 2013).

\section{Conclusions}

Within limitations of this randomized clinical study on type II diabetic patients that were controlled through all study period, it can be concluded that both immediate and delayed loading protocols for flapless implantretained mandibular overdentures achieve a successful

Table 3 Comparison between group I (immediate loading) and group II (delayed loading) mesial and distal ( $M \pm$ SD in mm) implant marginal bone loss after 6 and 12 months

\begin{tabular}{lllll}
\hline & Follow-up time & Group I, $M \pm$ SD $(\mathrm{mm})$ & Group II, M \pm SD $(\mathrm{mm})$ & $P$ value \\
\hline Mesial & After 6 months & $0.82 \pm 0.11$ & $0.79 \pm 0.1$ & $0.5^{*}$ \\
& After 12 months & $1.01 \pm 0.11$ & $1.03 \pm 0.12$ & $0.6^{*}$ \\
Distal & After 6 months & $0.75 \pm 0.09$ & $0.74 \pm 0.08$ & $0.7^{*}$ \\
& After 12 months & $1.04 \pm 0.04$ & $1.38 \pm 0.23$ & $0.001^{* *}$ \\
\hline
\end{tabular}

$M$ mean, $S D$ standard deviation, $P$ probability level

*Insignificantly difference

**Significantly difference 


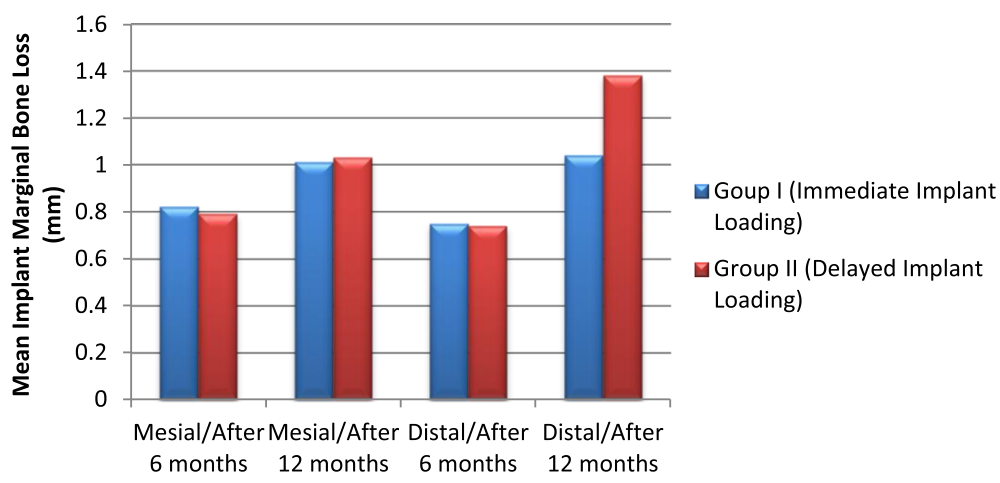

Fig. 4 Bar charts comparing between group I (immediate loading) and group II (delayed loading) mesial and distal ( $M \pm$ SD in millimeter) implant marginal bone loss after 6 and 12 months

clinical outcome regarding osseointegration and preservation of marginal bone height.

\section{Recommendations}

1. Further prospective clinical studies are suggested to evaluate peri-implant soft tissues outcomes, longterm dental implant rehabilitation follow-up, and patient satisfaction.

2. Finite element, biological, and other studies are recommended on the long-term of dental implants serviceability due to the plenty of commercially available designs, materials, surface treatments, and the different loading protocol combined with variable prosthodontics.

\section{Abbreviations}

CAD/CAM: Computer Aid Design/Computer Aid Manufacturer; CBCT: Cone beam computed tomography; DICOM: Digital Imaging and Communication in Medicine; DM: Diabetes mellitus; NRC: National Research Centre

\section{Acknowledgements}

The authors thank the National Research Centre, Cairo, Egypt, for supporting this study.

\section{Ethics approval and consent participate}

The study protocol was approved by the Ethics Committee of the National Research Center, Cairo, Egypt. All patients were informed thoroughly about the study, and each patient was asked to sign a consent form. Only motivated and cooperative patients who accepted the periodic recall visits and agreed to sign the consent form were enrolled.

\section{Authors' contributions}

EM introduced the idea of the research, started the collection of the required cases, inserted the implants, and wrote the draft of the manuscript. HG inserted the implants, carried out the follow-up for the cases, performed data collection, and statistically analyzed the results. AM carried out the follow-up for the cases, performed data collection, and revised the manuscript. Both authors contributed to this project and article equally. All authors read and approved the final manuscript.

\section{Funding}

This research was funded form National Research Centre, Cairo, Egypt, in a project no. 11010203 entitled "Dental care to improve quality of life for diabetic geriatric patients"

\section{Availability of data and materials}

This article under the terms of the Creative Commons AttributionNonCommercial-NoDerivs License, which permits use and distribution in any medium, provided the original work is properly cited, the use is Non-commercial and no modifications or adaptations are made. Materials were available in the market and data was collected in a smooth manner

\section{Consent for publication}

Obtained from the author.

\section{Competing interests}

The authors declare that they have no conflict of interest.

\section{Author details}

${ }^{1}$ National Research Centre, Cairo, Egypt. ${ }^{2}$ Batterjee Medical College, Jeddah, Saudi Arabia.

Received: 10 May 2019 Accepted: 12 November 2019 Published online: 23 December 2019

\section{References}

Albaker AM (2012) The oral health-related quality of life in edentulous patients treated with conventional complete dentures. Gerodontology:1-6

Albrektsson T, Brunski J, Wennerberg A (2009) 'A requiem for the periodontal ligament' revisited. Int J Prosthodont 22:120-122

Albrektsson T, Zarb GA (1993) Current interpretations of the osseointegrated response: clinical significance. Int J Prosthodont. 6:95-105

Alqutaibi AY, Kaddah AF (2016) Attachments used with implant supported overdenture. Int Dent Med J Adv Res 2:1-5

Attard NJ, Zarb GA (2004) Long-term treatment outcomes in edentulous patients with implant overdentures: the Toronto study. Int J Prosthodont 17:425-433

Balshi SF, Wolfinger GJ, Balshi TJ (2006) Surgical planning and prosthesis construction using computed tomography, CAD/ CAM technology and the Internet for immediate loading of dental implants. J Esthet Restor Dent. 18: 312-325

Beikler T, Flemmig TF (2003) Implants in the medically compromised patient. Crit Rev Oral Biol Med. 14(4):30516

Bornstein MM, Al-Nawas B, Kuchler U, Tahmaseb A (2014) Consensus statements and recommended clinical procedures regarding contemporary surgical and radiographic techniques in implant dentistry. Int J Oral Maxillofac Implants 29(Suppl):78-82

Calvet HM, Yoshikawa TT (2001) Infections in diabetes. Infect Dis Clin North Am. 15(2):407-421

Chiapasco M, Abati S, Romeo E, Vogel G (2001) Implant-retained mandibular overdentures with Branemark system MKII implants: a prospective comparative study between delayed and immediate loading. Int J Oral Maxillofac Implants 16:537-546

Craig RG, Powers JM (2012) Restorative Dental Materials, 13th edn

Di Giacomo GA, da Silva JV, da Silva AM, Paschoal GH, Cury PR, Szarf G (2012) Accuracy and complications of computer-designed selective laser sintering 
surgical guides for flapless dental implant placement and immediate definitive prosthesis installation. J Periodontol. 83:410-419

Doundoulakis JH, Eckert SE, Lindquist CC, Jeffcoat MK (2003) The implantsupported overdenture as an alternative to the complete mandibular denture. J Am Dent Assoc. 134:1455-1458

Engelhardt S, Papacosta P, Rathe F, Özen J, Jansen JA, Junker R et al (2015) Annual failure rates and marginal bone level changes of immediate compared to conventional loading of dental implants. A systematic review of the literature and meta-analysis. Clin Oral Implants Res 26:671-687

Esposito M, Grusovin MG, Maghaireh H, Worthington HV (2013) Interventions for replacing missing teeth: different times for loading dental implants. Cochrane Database Syst Rev. 28(3):CD003878

Gastaldi G, Vinci R, Ferrini F, Giorgio G (2017) Capparé. P. Immediate versus delayed loading of a new conical connection implant in the esthetic zone: a randomized study with 2-year follow-up. Osseointegration. 9(3):271-275

Goodman S, Wang JS, Doshi A, Aspenberg P (1993) Difference in bone ingrowth after one versus two daily episodes of micromotion: experiments with titanium chambers in rabbits. J Biomed Mater Res 27:1419-1424

Goodman SB (1994) The effects of micromotion and particulate materials on tissue differentiation. Bone chamber studies in rabbits. Acta Orthop Scand Suppl 258:1-43

Khader YS, Dauod AS, El-Qaderi SS, Alkafajei A, Batayha WQ (2006) Periodontal status of diabetics compared with non-diabetics: a meta-analysis. J Diabetes Complications. 20:59-68

Kushaldeep, Tandan A, Upadhyaya V, Raghuvanshi M (2018) Comparative evaluation of the influence of immediate versus delayed loading protocols of dental implants: a radiographic and clinical study. J Indian Prosthodontic Soc 18(2):131-138

Lambade D, Lambade P, Gundawar S (2014) Implant supported mandibular overdenture: a viable treatment option for edentulous mandible. J Clin Diagn Res. 8(5):ZD04-ZD06

Liddelow GJ, Henry PJ (2007) A prospective study of immediately loaded single implant-retained mandibular overdentures: preliminary one-year results. J Prosthet Dent 97(6, suppl):S126-SS37

Ma S, Tawse-Smith A, Thomson WM, Payne AG (2010) Marginal bone loss with mandibular two-implant overdentures using different loading protocols and attachment systems: 10-year outcomes. Int J Prosthodont. 23:321-332

Meijer HJ, Batenburg RH, Raghoebar GM, Vissink A (2004) Mandibular overdentures supported by two Brånemark, IMZ or ITI implants: A 5-year prospective study. J Clin Periodontol. 31:522-526

Meijer HJ, Raghoebar GM, Batenburg RH, Visser A, Vissink A (2009) Mandibular overdentures supported by two or four endosseous implants: a 10-year clinical trial. Clin Oral Implants Res. 20:722-728

Misch CE. Contemporary implant dentistry. Elsevier Mosby; 2008. p. 15, 134-141, 294-299, 300-308, 421-466, 654, 812-813, 818, 833, 1073

Naert I, Alsaadi G, van Steenberghe D, Quirynen M (2004) A 10-year randomized clinical trial on the influence of splinted and unsplinted oral implants retaining mandibular overdentures: peri-implant outcome. Int J Oral Maxillofac Implants. 19:695-702

Oates TW, Huynh-Ba G, Vargas A, Alexander P, Feine J (2013) A critical review of diabetes, glycemic control, and dental implant therapy. Clin Oral Impl Res. 24:117-127

Ochi M, Kanazawa M, Sato D, Kasugai S, Hirano S, Minakuchi S (2013) Factors affecting accuracy of implant placement with mucosa-supported stereolithographic surgical guides in edentulous mandibles. Comput Biol Med. 43:1653-1660

Olson JW, Shernoff AF, Tarlow JL, Colwell JA, Scheetz JP, Bingham SF (2000) Dental endosseous implant assessments in a type 2 diabetic population: a prospective study. Int J Oral Maxillofac Implants. 15(6):811-818

Rani I, Shetty J, Reddy V (2017) A comparison of peri-implant strain generated by different types of implant supported prostheses. J Indian Prosthodont Soc 17:142-148

Romero-Ruiz MM, Mosquera-Perez R, Gutierrez-Perez JL, Torres-Lagares D (2015) Flapless implant surgery: a review of the literature and 3 case reports. J Clin Exp Dent. 7(1):e146-e152

Sanna AM, Molly L, van Steenberghe D (2007) Immediately loaded CAD-CAM manufactured fixed complete dentures using flapless implant placement procedures: a cohort study of consecutive patients. J Prosthet Dent. 97 : 331-339

Sato D, Kanazawa M, Kim YK, Yokoyama S, Omura Y, Ozeki M, Minakuchi S, Kasugai S, Baba K (2016) Immediate loading of two freestanding implants placed by computer-guided flapless surgery supporting a mandibular overdenture with magnetic attachments. J Prosthodont Res. 60(1):54-62

Schwartz-Arad D, Kidron N, Dolev E (2005) A long-term study of implants supporting overdentures as a model for implant success. J Periodontol. 76: $1431-1435$

Shor A, Goto Y, Shor K (2007) Mandibular two-implant retained overdenture: prosthetic design and fabrication protocol. Compendium. 28(2):28-32

Stricker A, Gutwald R, Schmelzeisen R, Gellrich NG (2004) Immediate loading of 2 interforaminal dental implants supporting an overdenture: clinical and radiographic results after 24 months. Int J Oral Maxillofac Implants. 19(6):868872

Swali S (2013) Implants in diabetic patients. A Review. Int J Oral Implantol Clin Res. 4(1):30-35

Szmukler-Moncler S, Salama H, Reingewirtz Y, Dubruille JH (1998) Timing of loading and effect of micromotion on bone dental implant interface: review of experimental literature. J Biomed Mater Res 43:192-203

Thu KM, Thuy VL, Kanazawa M, Minakuchi S (2014) Evidences of applicability of implant supported overdentures during present decade. a review. Online, pp 32-41

Vidyasagar L, Aspe P (2003) Biological response to dental implant loading/ overloading. Implant overloading: Empiricism or science? Stomatologija Baltic Dent Maxillofac J 5:83-89

Wennström J, Palmer R (1999) Consensus report of Session C. In: Lang NP, Karring T, Lindhe J (eds) Proceedings of the $3^{\text {rd }}$ European Workshop on Periodontology. Quintessence, Berlin, pp 255-259

Zarb GA, Albrektsson T (1998) Consensus report: Towards optimized treatment outcomes for dental implants. J Prosthet Dent. 80:641

\section{Publisher's Note}

Springer Nature remains neutral with regard to jurisdictional claims in published maps and institutional affiliations.

\section{Submit your manuscript to a SpringerOpen ${ }^{\circ}$ journal and benefit from:}

- Convenient online submission

- Rigorous peer review

- Open access: articles freely available online

High visibility within the field

- Retaining the copyright to your article

Submit your next manuscript at $\boldsymbol{\nabla}$ springeropen.com 